\title{
Epidemiological Profile of Leprosy Patients Attending in A Tertiary Care Centre in Post Leprosy Elimination Era
}

\author{
*Dr. Kulkarni S.K. \\ Assistant Professor, Department Of Community Medicine, DR.S.C.G.M.C. Vishnupuri Nanded, 431606 \\ Maharashtra, India
}

\begin{abstract}
:
Background: Leprosy, a disabling infectious disease, is a major public health problem in some regions, requiring knowledge of its epidemiological variations so that strategies for case detection and disease control can be subsidized. Objectives: This study aims to study epidemiological profile of leprosy patients attending Department of Dermatology, Venereology and Leprosy. Materials \& Methods: Retrospective study of medical records of 111 diagnosed leprosy cases between January to December 2015 were analysed at the Department of Dermatology, Venereology and Leprosy, DR.S.C.G.M.C. vishnupuri Nanded, India. Results: Maximum no. $62(55.85 \%)$ of leprosy patients are in the age group of 16-35 yrs. Most 76(68.46\%) of patients were male followed by female. Least no. $9(8.10 \%)$ of patients are in $<15$ yrs of age. Most of leprosy patients are from rural area i.e. 91(81.98\%) than urban area i.e. 20(18.01). Most common i.e. 71(63.96\%) type of leprosy is multibacillary leprosy which is followed by paucibacillary type i.e. 40(36.03\%). Deformities are present in 9(8.10\%) leprosy patients out of which claw hand 5(4.50) is the most common deformity. Conclusion: The results of this study point to a high circulation of lepra bacilli in the community in the "elimination era" and also highlight the need for early diagnosis and appropriate treatment at the field level to prevent spread of bacilli and development of disabilities. By early detection and increasing the duration of therapy and increasing community awareness utilising Informatoin, Education and Communication (IEC) at all levels, we can hope to achieve the dream of leprosy free India.
\end{abstract}

Keywords: Leprosy, multibacillary, new cases, paucibacillary, post leprosy elimination era.

\section{Introduction}

Leprosy is one of those few chronic infectious diseases that are associated with serious physical and functional disabilities affecting the skin and peripheral nerves. Mycobacterium leprae, the causative organism of this malady, is transmitted by droplet spread which is facilitated by close contact. Although leprosy was the first infectious disease to have its etiological agent discovered, it still remains a disease of public health concern because of the case load and the social stigma attached to the disease ${ }^{[1]}$.

Leprosy has afflicted humanity since time immemorial. There are many countries in Asia, Africa and Latin-America with a large number of leprosy cases. It still remains an important cause of disability years after WHO adopted the resolution to "eliminate leprosy as a public health problem by the year 2000 " way back in $1991^{[6,7]}$. WHO declared leprosy elimination (reported prevalence less than one case per 10,000 population) from most of the countries where it was considered a major public health problem in $1985^{[10]}$. However, pockets of high endemicity still persists in some regions of our country. Although India achieved elimination from leprosy in 2006 a large proportion of leprosy cases reported globally constitute from India. Having a national prevalence of 0.72 per 10,000 during march 2009 with only three states/union territories [UT] lagging behind the elimination target ${ }^{[8]}$. Even in states and Union Territories that have achieved elimination a few districts and blocks continue to have a prevalence of $>1 / 10,000$. Special plans such as Focussed Leprosy Elimination Plan (FLEP) have been launched under National Leprosy Eradication Programme (NLEP) to bring down the prevalence in these high endemic areas of our country ${ }^{[9]}$. In many countries the proportion of Multi Bacillary[MB]leprosy cases among new cases remains still high like for example democratic republic of Congo(72\%), Indonesia(81\%), Cuba 83(\%) and Kenya (99\%).Not only the indicator of active transmission, that is proportion of children among new cases remains high $(>20 \%)$ in countries like Liberia, Domenican republic, Indonesia, but also shows increase in Nepal and Sudanupto $5 \%$ in the past few years and continues to remain

In 2011, of the total 219,075 new leprosy cases reported globally, 58.1\% were detected only in India ${ }^{[7]}$. According to WHO weekly epidemiological report 2013 the southeast Asian region accounts for $71 \%$ of new cases detected worldwide. Out of the global total 2,32,857 new patients 1,34,752 have been detected in India in $2012^{[8]}$.

Leprosy is regarded as a special disease because 1. Slow, generation time of the bacillus( two weeks). This results in long incubation period (average 5-7 yrs),a very slow development of pathology, a slow and insidious clinical evolution and unclear epidemiological pattern .2. The bacillus has never been conclusively 
grown in artificial medium and consequently the bacteriology of leprosy was greatly delayed until 1960 when limited growth in mice was achieved. 3. This is the only bacillary disease with a predilection for nerve tissue. 4 .Man alone gets leprosy, and is the reservoir of infection, although naturally infected armadillos have been found in the Southern USA and primates in Africa. 5. Leprosy is the best example of a disease which has a spectrum from complete absence of resistance by the host to effective immunity, which is often accompanied by extreme and destructive hypersensitivity. In lepromatous leprosy bacillary invasion is such that the number of bacilli in the dermis can reach 109 per gram tissue. In tuberculoid leprosy on the other hand the cell mediated response to the presence of bacilli is so violent that it continues in the presence of a bacillary population which is too small to be detectable .6. Leprosy deforms and disables but seldom kills, so that those it has crippled live on ,getting steadily worse ,their deformities visible to all the community. M.leprae has a preference for temperature less than $370 \mathrm{C}$ for its optimal growth.so it predominantly involves skin, nasal mucosa and peripheral nerves where the temparature is lower than core body temparature. ${ }^{[21,22]}$

Transmission: Untreated multibacillary cases are the most important source of infection compared to pauci bacillary cases.

With the advent of multidrug therapy (MDT), the prevalence and incidence of the disease has drastically reduced. Compared to more than 5 million cases diagnosed in the year 1990, only 244,796 new cases of leprosy were detected globally in the year $2009^{[3]}$. Among the African and Southeast Asian countries that report the highest numbers, India leads the list by contributing the majority of the cases. This situation is deplorable, considering the fact that on January 30, 2006, India announced the elimination of leprosy at the national level ${ }^{[4]}$. About 127,295 new cases are still detected at the end of the year 2011 in India with more than $10 \%$ child cases, indicating active transmission of leprosy in Indian communities ${ }^{[5]}$.

The epidemiology of leprosy in relation to its geographical distribution remains somewhat unclear. The main historically endemic areas in the world have tropical climate with high temperatures and rainfall; however, leprosy has also presented high incidences in temperate and cold regions ${ }^{[2]}$.

With this mentioned background kept in mind the present study was planned to conduct to review the epidemiolgical profile of leprosy patients attending a tertiary care centre.

\section{Materials \& Methodology}

This study was a retrospective analysis of all 111 leprosy cases who registered for treatment at the Dermatology department of the Government Medical College, Nanded from January 2015 to December 2015. Ethical clearance was obtained from the institutional ethics committee prior to start of the study. A diagnosis of leprosy was made, when a patient presented with any of the cardinal features of leprosy (asymptomatic hypopigmented or erythematous skin lesion with definite loss or impairment of sensation or thickened peripheral nerve with sensory impairment in the area supplied by the nerve or skin smear positive for acid fast bacilli). A pre-set proforma was used to collect data regarding age, sex, possible source of contact, clinical findings and investigations from previous case records. Clinical features including size, site, morphology and number of skin lesions were noted. Nerve function impairment (NFI) when present was charted out. Sensory impairment was detected by the inability or reduced ability to appreciate temperature, pain and fine touch. Test tubes containing water at $40^{\circ} \mathrm{C}$ and at $25^{\circ} \mathrm{C}$ were used to test temperature sensation, pain sensation was tested using pin prick and a wisp of cotton was used to check fine touch. Motor impairment was diagnosed when less than grade 5 power was recorded on voluntary muscle testing.

The WHO classification (1998) for leprosy control programmes: The patients are categorised into 1. Paucibacillary single lesion leprosy ( SLPB) 2.Paucibacillary leprosy (2-5 skin lesions) 3. Multibacillary leprosy - six or more skin lesions and also smear positive lesions. Presently in India the number of nerves involved is also taken into consideration while categorising the patients into paucibacillary and multibacillary types as per the criterion laid down under the National Leprosy Eradication programme( NLEP) of government of India. Classification under NLEP, India (2009)

\begin{tabular}{|l|l|l|l|}
\hline Sr.No. & Characteristics & PB & MB \\
\hline 1. & skin lesions & $1-5$ lesions & 6 and above \\
\hline 2. & $\begin{array}{l}\text { Peripheral nerve } \\
\text { involvement }\end{array}$ & $\begin{array}{l}\text { No nerve /only one nerve } \\
\text { with or without 1-5 lesions }\end{array}$ & $\begin{array}{l}\text { More than one nerve } \\
\text { irrespective of the number of } \\
\text { skin lesions }\end{array}$ \\
\hline 3. & Skin smears & Negative at all sites & Positive at any site \\
\hline
\end{tabular}

Note: if skin smear is positive, irrespective of number of skin and nerve lesions ,the disease is classified as MB leprosy but if skin smear is negative it is classified on the basis of the number of skin and nerve lesions. Presently, the WHO classification for treatment purposes and Ridley-Jopling classification for academic and research work is being followed satisfactorily. 
Management of deformities was done according to grade and type of deformity. Type1 deformities of hands and feetwere managed by giving proper education and demonstration about how home care can be done. Type 2 deformities were managed according to the disability present. Proper wound care and dressing of ulcers if present was done.

\section{Results}

Table no. 1 of age \& sex wise distribution of leprosy patients show that out of 111 leprosy patients maximum no. 62(55.85\%) of leprosy patients are in the age group of 16-35 yrs. Most $76(68.46 \%)$ of patients were male followed by female. Least no. $9(8.10 \%)$ of patients are in $<15$ yrs of age. TABLE no. 3 showed that most of leprosy patients are from rural area i.e. 91(81.98\%) than urban area i.e. 20(18.01). TABLE no. 2 of distribution of leprosy patients according to clinical types show that the most common i.e. 71(63.96\%) type of leprosy is multibacillary leprosy which is followed by paucibacillary type i.e. 40(36.03\%). TABLE no. 4In the present study 102(91.89\%) patients don't have any deformity. Deformities are present in $9(8.10 \%)$ leprosy patients out of which claw hand 5(4.50) is the most common deformity.

TABLE 1 : Age \& sexwise distribution of leprosy patients

\begin{tabular}{|l|l|l|l|}
\hline Age in yrs & Male no.(\%) & Female no.(\%) & Total no.(\%) \\
\hline$<15$ yrs & $7(6.30)$ & $2(1.80)$ & $9(8.10)$ \\
\hline $16-35$ & $43(38.73)$ & $19(17.11)$ & $62(55.85)$ \\
\hline $36-50$ & $16(14.41)$ & $9(8.10)$ & $25(22.52)$ \\
\hline$>50 y r s$ & $10(9.00)$ & $5(4.50)$ & $15(13.51)$ \\
\hline Total & $76(68.46)$ & $35(31.53)$ & $111(100)$ \\
\hline
\end{tabular}

table 2 : Distribution of leprosy patients according to clinical types

\begin{tabular}{|l|l|l|l|}
\hline Type & Male no.(\%) & Female no.(\%) & Total no.(\%) \\
\hline Paucibacillary leprosy & $29(26.12)$ & $11(9.91)$ & $40(36.03)$ \\
\hline Multibacillary leprosy & $51(45.94)$ & $20(18.01)$ & $71(63.96)$ \\
\hline Total & $80(72.07)$ & $31(27.92)$ & $111(100)$ \\
\hline
\end{tabular}

Table 3 : Area wise distribution of leprosy patients

\begin{tabular}{|l|l|l|l|}
\hline Area & Male no.(\%) & Female no. $(\%)$ & No. $(\%)$ \\
\hline Urban & $12(10.81)$ & $8(7.20)$ & $20(18.01)$ \\
\hline Rural & $71(63.96)$ & $20(18.01)$ & $91(81.98)$ \\
\hline Total & $83(74.77)$ & $28(25.22)$ & $111(100)$ \\
\hline
\end{tabular}

TABLE 4 : Distribution of deformities amongst leprosy patients.

\begin{tabular}{|l|l|l|}
\hline Deformities & No. & $\%$ \\
\hline No deformities & 102 & 91.89 \\
\hline Absorption of toes & 0 & \\
\hline Claw hand & 5 & 4.50 \\
\hline Fissures & 0 & \\
\hline Foot drop & 0 & \\
\hline Partial claw hand & 1 & 0.90 \\
\hline Ulcer & 1 & 0.90 \\
\hline Wrist drop & 1 & 0.90 \\
\hline Logopthalmus & 1 & 0.90 \\
\hline TOTAL & 111 & 100 \\
\hline
\end{tabular}

\section{Discussion}

The present study indicates the high load of undiagnosed cases in the community. Leprosy affects people across all age groups. The incidence was maximum in the age group of 16-35 years (42\%). We believe marriageable age as being one of the reasons for increased self reporting at this age especially to rule out vitiligo which has huge social stigma in this region. Leprosy is known to have a male preponderance. In our study too as compared to the study conducted by Jindal et $\mathrm{al}^{[16]}$ in 2009 majority of the cases were males, 34(75.55\%) cases out of 45.This is the general pattern in India. Increased mobility, frequent interaction with community leads to increased opportunity for contacts. Also self reporting is higher among males. Local beliefs like taking a dip in holy water in a nearby village and illiteracy adds to the existing problem in both men and women alike.

The percentage of $\mathrm{MB}$ cases $(86.9 \%)$ in our study was significantly higher than PB cases. The corresponding figure from another tertiary hospital in Delhi (1994-2009) was reported to be $80.57 \% .{ }^{[17]}$ Another retrospective study from Satara district in Maharashtra reported 53.6\% MB cases among new cases in the year 2007-08.[15] The high proportion of MB cases in our study could be a sign of existence of inaccessible pockets of population harboring undiagnosed leprosy patients for a long time. 
In the present study $102(91.89 \%)$ patients don't have any deformity. Deformities are present in $9(8.10 \%)$ leprosy patients out of which claw hand $5(4.50 \%)$ is the most common. Number of patients presenting with deformitiesduring the study period were less $9(8.10 \%)$ which is mainly because of early detection of cases. Dr.G.Swarnakumari et $\mathrm{al}^{[19]} 58(29.9 \%)$ patients showed deformities in the form of claw hand, foot drop, trophic ulcers and resorption of digits, which suggests delay in diagnosis, treatment and lack of disease awareness in the patients. Nagabhushanam[20] found claw hand deformity in $17.3 \%$ of patients and more of the patients revealed wrist drop, out of 410 patients. Though MDT has made a sea change in profile of the disease, disabilities continue to be a major problem. Leprosy has been a feared and stigmatised disease mainly because of the deformities associated with it.

Delivery of better health care system and management of better quality leprosy services can shoulder to a great extent while good referral system can bring faith in the minds of masses. Political will power, vision and mission of the government can prove to be a guiding star and strategies for eradication, elimination and prevention of the disease by professional community should go hand in hand in perfect harmony with the government

It was reported by Ganpati et al., in 2005, that "the pool of leprosy patients with reaction, neuritis and its sequelae and those needing rehabilitation contributing to the disease burden in the community will far outnumber the active cases needing MDT". That day has sadly arrived. In our zeal to "eliminate" leprosy, we seem to be reaching a juncture where number of cases is less, but the disease burden is far more. Recent publications by Singal et al. and Prasad et al. reinforce the fact that single-minded focus on MDT, lack of proper fund allocation and integration with General health services is leading to an inadequate control of the leprosy burden. The health care system may land up repeating the monumental mistakes made earlier with the Malaria eradication programme. An early divergence of focus as well as funds lead to resurgence of malaria in the 1970s which has till date remained a major public health problem. In spite of the established fact that leprosy is least infectious and completely curable, the social stigma still lingers and remains a major obstacle to self-reporting and early treatment. Early detection depends almost completely on voluntary reporting which implies awareness of the disease and its treatment facilities. Our data from a tertiary care referral center shows that an early active search for cases may be needed. ${ }^{[14]}$

\section{Conclusion}

Health education and publicity about leprosy, with emphasis on early presentation for diagnosis and the likelihood of cure by multiple drug therapy. Self presentation for diagnosis should be greatly encouraged. Increasing community awareness utilising Information, Education, and Communication (IEC) activities at all levels and in all states with more emphasis on endemic states should be launched. The message should be in local language to be more effect. Eradication of leprosy may be a politically desirable aspiration but the scientific case for such a strategy cannot be justified at the moment. Overzealous attempts to achieve elimination of leprosy at all levels and the pressure to achieve desired results by stipulated date has resulted in declaration of leprosy as eliminated under various programs. However large number of new cases have been detected in recent years because of adoption of new strategy, modified leprosy elimination campaign(MLEC) and effective health education campaign(Mandal 2001)[15]. Early detection of cases is due to better awareness in the community about the disease. The current reality is that there is need to sustain and provide quality leprosy services to all persons through general health system, including good referral system. Efforts need to be made to reduce deformity through early detection, self care, physiotherapy, and developing sound surveillance systems. The decision regarding declaration of strategies pertaining to eradication, elimination or control should be left to scientific scrutiny and techno- managerial considerations. In order to sustain "elimination", current leprosy control activities should be continued with full force even. Active surveillance is still needed to detect the subclinical cases and undiagnosed cases.

Limitations: This was due to cases from departmental records, hence bias in reporting cannot be totally ruled out. We could include only the cases presenting to our own center which happens to be tertiary care referral center. It could be safely assumed that more complicated cases were being recorded. Community-based surveys covering the district population could help clarify this issue. Even now , around a quarter of a million new cases are recorded each year all over the world, ranking leprosy as the 11th highest cause of mortality and 12th highest cause of morbidity from neglected cases. Perhaps we are failing to understand some important aspects of the disease's natural history. Prospect of elimination has discouraged the research in the field There is disappointingly very little progress in the development of an effective vaccine for leprosy.

\section{References}

[1]. J. Khubchandani, "State of the globe: many challenges of the multifaceted leprosy," Journal of Global Infectious Diseases, vol. 3, pp. 315-316, 2011. View at Publisher . View at Google Scholar 
[2]. M. C. C. Magalhães and L. I. Rojas, “Time trends of Hansen's disease in Brasil,” Revista Brasileira de Epidemiologia, vol. 8, no. 4, pp. 342-355, 2005. View at Google Scholar

[3]. World Health Organization, "Global Leprosy situation 2010," The Weekly Epidemiological Record, vol. 35, pp. 337-348, 2010. View at Google Scholar

[4]. G. P. S. Dhillon, "NLEP_Current situation and strategy during the 11th plan period (2007-2012)," Journal of the Indian Medical Association, vol. 104, no. 12, pp. 671-672, 2006. View at Google Scholar · View at Scopus

[5]. "NLEP_Progress report for the year 2011-2012," 2012, http://www.nlep.nic.in/data.html.

[6]. Sehgal VN, Sardana K, Dogra S. The imperatives of leprosy treatment in the pre and post global leprosy elimination era: appraisal of changing the scenario to current status. J Dermatolog Treat.2008; 19(2):82-91.

[7]. Saunderson PR. Leprosy elimination: not as straightforward as it seemed. Public health Rep.2008 Mar-Apr; 123(2):213-216.

[8]. NLEP - Progress report for the year 2008-2009 ending on 31st march 2009.Central Leprosy Division. Directorate of health services, Govt. of India, New Delhi, 2009.

[9]. Guidelines for NLEP - Situational Activity Plan- 2007. Central Leprosy Division. Directorate of Health Services, Govt. of India, New Delhi, 2007.

[10]. World Health Organization. Global leprosy situation, 2009. Weekly Epidemiological Record, No. 33, 2009; 84: 333-340

[11]. Singal A, Sidharth S. Leprosy in post-elimination era in India: Difficult journey ahead. Indian journal of dermatology. 2013; 58(6) 443.

[12]. Dogra S, Narang T, Kumar B. Leprosy - evolution of the path to eradication. Indian J Med Res 2013;137: 15-35

[13]. WHO: Weekly Epidemiological Record (WER). 30 August 2013, vol. 88, 35.p.365-380.

[14]. Leprosy Scenario at a Tertiary Level Hospital in Delhi: A 5-year Retrospective Study Namrata Chhabra, Chander Grover, Archana Singal, Sambit Nath Bhattacharya, and Ramandeep Kaur Indian J Dermatol. 2015 Jan-Feb; 60(1): 55-59.

[15]. Mandal BC. Present leprosy situation in India and the decade long experience of this correspondent. Nihon Hansenbyo Gakkai Zasshi. 2001;70:25-29.

[16]. Jindal N, Shanker V, Tegta GR, Gupta M, Verma GK. Clinicoepidemiological trends of leprosy in Himachal Pradesh: a five year study. Indian J Lepr. 2009; 81: 173-179.

[17]. Tiwary PK, Kar HK, Sharma PK, Gautam RK, Arora TC, Naik H, et al. Epidemiological trends of leprosy in an urban leprosy centre of Delhi: A retrospective study of 16 years. Indian J Lepr. 2011;83:201-8. [PubMed]

[18]. Mohite RV, Durgawale PM, Evaluation of national leprosy eradication programme in Satara District, Maharashtra. Indian J Lepr. 2011;83:139-43. [PubMed]

[19]. Dr.G.Swarnakumari et al. A Study of Clinical Profile of Leprosy in Post Leprosy Elimination Era. IOSR Journal of Dental and Medical Sciences (IOSR-JDMS) e-ISSN: 2279-0853, p-ISSN: 2279-0861.Volume 14, Issue 11 Ver. VIII (Nov. 2015), PP 04-12 www.iosrjournals.org

[20]. Nagabhushanam P.Gross deformities in leprosy. Indian J Dermat \& Vener 1967;33:70-72

[21]. Anthony D.M.Bryceson.Leprosy,3rd edition.pp 1,2

[22]. Hemanth kumar Kar.IAL Text book of leprosy2010,.p28-30,145-150,357 